\title{
Diaphragm plication: When and why to do it
}

\author{
Peter J. Gruber, MD, PhD
}

From the Departments of Surgery, Stem Cell Biology, and Regenerative Medicine, Keck School of Medicine, University of Southern California, Los Angeles, Calif.

Disclosures: Author has nothing to disclose with regard to commercial support.

Received for publication July 10, 2017; accepted for publication July 25, 2017; available ahead of print Sept 1, 2017.

Address for reprints: Peter J. Gruber, MD, PhD, Adjunct Professor of Surgery, Stem Cell Biology, and Regenerative Medicine, Keck School of Medicine, University of Southern California, 1450 Biggy St, 4517 NRT, Los Angeles, CA 90033 (E-mail: peter.gruber@med.usc.edu).

J Thorac Cardiovasc Surg 2017;154:1712-3

$0022-5223 / \$ 36.00$

Copyright $(c) 2017$ by The American Association for Thoracic Surgery

http://dx.doi.org/10.1016/j.jtcvs.2017.07.042

Paralysis of diaphragm is a common cause of delayed recovery and excessive morbidity after pediatric cardiac surgery. The consequences of this complication can be serious, especially in neonates, in young infants, and after single-ventricle palliation. ${ }^{1}$ The pathophysiology of diaphragm paralysis is complex, and the primary event, diaphragm dysfunction, is only one part of the picture. Decreased movement, or in the extreme case paradoxical cephalic motion of the diaphragm during inspiration, reduces air entry on the ipsilateral side. It can also shift a mobile mediastinum away from the affected side, secondarily impairing function of the contralateral lung. It is also clear that diaphragmatic denervation causes muscle fibrosis, fiber atrophy, and necrosis. Although there is an array of opinion on the need and timing of diaphragm plication, it is widely accepted that, in select cases, surgical intervention can provide rapid improvement and facilitate weaning from the ventilator. ${ }^{2}$ Several reviews have examined this vexing problem that has surely affected patients of all congenital surgeons with sufficient experience and age. ${ }^{3}$ The questions are which patients are best served by diaphragm plication and when to do it.

Gibson's erudite 1989 review of diaphragmatic paresis ${ }^{4}$ put a number of important issues in focus. With denervation, striated skeletal muscles atrophy, with a reduction in muscle fiber size and diaphragmatic function. The patterns and extent of atrophy vary, however, with different types and degrees of injury, animal models, and ages. If denervation is complete, all muscle fibers will eventually atrophy, but the precise course is unpredictable. Indeed, with partial motor denervation, atrophic fibers are observed with groups of normal fibers and partially functional muscle. ${ }^{5}$ The degree to which atrophy occurs relative to recovery, and how this affects function, is incompletely understood. In addition to atrophy, a parallel process of fibrosis occurs, although the degree and extent of this fibrosis is also unpredictable. Functionally, diaphragmatic fibrosis is similar to plicated muscle. ${ }^{6}$ Thus, management of diaphragmatic paralysis as a result of phrenic nerve injury is still controversial, with several options available to the surgeon. First, one can proceed with immediate diaphragmatic plication to reduce the need for mechanical ventilation,

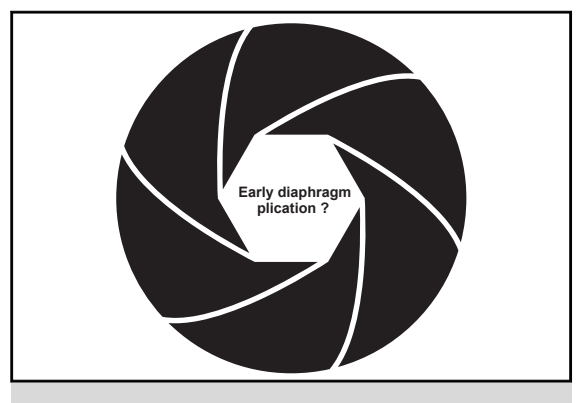

Early diaphragm plication.

Central Message

Diaphragm paralysis is a well-known and debated complication, and its morbidities can complicate patient management. More information about the biology of the disease is required for further progress.

See Article page 1715 .

duration of hospital stay, and pulmonary infections. Second, one can delay diaphragmatic plication for a period of weeks, a reasonable time for the spontaneous recovery that occurs in most patients. Third, one can take a conservative, nonoperative approach with prolonged mechanical ventilation, because improvement can occur as late as months later, thus avoiding operative and postoperative complications associated with plication. ${ }^{7}$ Where is the balance between an unnecessary operation and unnecessary waiting?

The article in this issue of the Journal by Floh and colleagues $^{8}$ adds to the literature by examining the advantages of "early plication" in children after cardiac surgery. This was a single-center, retrospective study in a 10-year period between 2002 and 2012. Patients $(n=6448)$ were considered if they underwent cardiac surgery and diagnostic ultrasound for diaphragmatic function. Floh and colleagues ${ }^{8}$ defined early plication as being performed at median of 6 days (2-21 days after diagnosis). Diaphragmatic paralysis was diagnosed in $2.5 \%$ of patients, and plication of the diaphragm was performed in $19 \%$ of those patients. The plication group was found to be both younger and more likely to have undergone deep hypothermic circulatory arrest. This group had longer durations of positive-pressure ventilation, intensive care unit stay, and hospital stay. Floh and

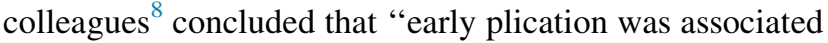
with a reduction in all intervals of care." These results are consistent with other studies that have found that younger patients with diaphragm paralysis are at higher risk of 
longer intubation than those older than 2 years and are associated with considerable morbidity. Eventual recovery of phrenic nerve function can still occur, however, in as many as $84 \%$ of children. ${ }^{9,10}$

Could a close study of those with diaphragm paresis lead to a better knowledge of recovery times, further stratifying those patients who need plication and those who do not? A focused effort on understanding the pathobiology of phrenic nerve damage in animals that better approximate human diaphragmatic function would be informative. With this information, accurate diagnostics might allow a more refined approach to the patient with diaphragm paralysis. This increasing precision of diagnosis and a thoughtful approach to surgical diaphragm plication should lead to both improved outcomes and fewer unnecessary operations.

\section{References}

1. Talwar S, Agarwala S, Mittal CM, Choudhary SK, Airan B. Diaphragmatic palsy after cardiac surgical procedures in patients with congenital heart. Ann Pediatr Cardiol. 2010;3:50-7.
2. Gallagher PG, Seashore JH, Touloukian RJ. Diaphragmatic plication in the extremely low birth weight infant. J Pediatr Surg. 2000;35:615-6.

3. Smith BM, Ezeokoli NJ, Kipps AK, Azakie A, Meadows JJ. Course, predictors of diaphragm recovery after phrenic nerve injury during pediatric cardiac surgery. Ann Thorac Surg. 2013;96:938-42.

4. Gibson GJ. Diaphragmatic paresis: pathophysiology, clinical features, and investigation. Thorax. 1989;44:960-70.

5. Torrejais MM, Soares JC, Matheus SMM, Francia-Farje LAD, Mello JM, Vicente EJ. Morphologic alterations resulting from denervation of the diaphragm in rats. Int. J. Morphol. 2012;30:1150-7.

6. Verin E, Marie JP, Tardif C, Denis P. Spontaneous recovery of diaphragmatic strength in unilateral diaphragmatic paralysis. Respir Med. 2006;100: 1944-51.

7. Commare MC, Kurstjens SP, Barois A. Diaphragmatic paralysis in children: a review of 11 cases. Pediatr Pulmonol. 1994;18:187-93.

8. Floh AA, Zafurallah I, MacDonald C, Honjo O, Fan C-P, Laussen PC The advantage of early plication in children diagnosed with diaphragm paresis. J Thorac Cardiovasc Surg. 2017;154:1715-21.e3.

9. Watanabe T, Trusler GA, Williams WG, Edmonds JF, Coles JG, Hosokawa Y. Phrenic nerve paralysis after pediatric cardiac surgery: retrospective study of 125 cases. J Thorac Cardiovasc Surg. 1987;94: 383-8.

10. Joho-Arreola AL, Bauersfeld U, Stauffer UG, Baenziger O, Bernet V. Incidence and treatment of diaphragmatic paralysis after cardiac surgery in children. Eur J Cardiothorac Surg. 2005;27:53-7. 